\title{
Influence of environmental factors on the spread of COVID-19 in Saudi Arabia
}

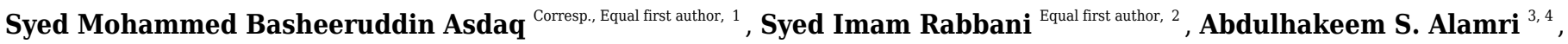 \\ Walaa F. Alsanie $^{3,4}$, Majid Alhomrani $^{3,4}$, Mohammed J. Al-Yamani $^{1}$ \\ 1 Department of Pharmacy Practice, College of Pharmacy, AlMaarefa University, Dariyah 13713, Riyadh, Saudi Arabia \\ 2 Department of Pharmacology and Toxicology, College of Pharmacy, Qassim University,, Qassim University, Buraydah, Saudi Arabia \\ 3 Centre of Biomedical Sciences Research (CBSR), Deanship of Scientific Research, Taif University, Saudi Arabia, Taif, Saudi Arabia \\ 4 Department of Clinical Laboratory Sciences, The Faculty of Applied Medical Sciences, Taif University, Taif, Saudi Arabia, Taif University, Taif, Saudi \\ Arabia \\ Corresponding Author: Syed Mohammed Basheeruddin Asdaq \\ Email address: sasdaq@gmail.com
}

Background: Coronavirus disease 2019 (COVID-19) has affected millions of people worldwide. The infection is mostly spread through the inhalation of infected droplets. Saudi Arabia is a vast country having different climatic conditions. Methods: The study evaluated the influence of environmental factors on the spread of COVID-19. Six zones (A to F) were classified depending on the climatic conditions. The study was conducted by retrospective analysis of COVID-19 records from the ministry of health between the months of September 2020 and August 2021. The environmental data such as average temperature $\left({ }^{\circ} \mathrm{C}\right)$, humidity $(\%)$, wind speed $(\mathrm{m} / \mathrm{s})$ and sun exposure $\left(\mathrm{kwh} / \mathrm{m}^{2}\right)$ were retrieved from official sites. The data was analyzed to determine the effect of these factors on the spread of COVID-19. SPSS IBM 25 software was used to conduct the analysis and $p$ $<0.05$ was considered to indicate the significance of the results. Results: According to the findings, the rate of infection was greater between April and July 2021. Six climatic zones experienced high temperatures, little humidity, consistent wind flow, and intense sun exposure throughout this time. The correlation study revealed a significant ( $p$ $<0.05$ )relationship between the environmental factors and the spread of COVID-19. The data suggested that during summer condition when the weather is hot, less humid, and steady wind flow with lots of sun exposure, the COVID-19 infection rate got augmented in Saudi Arabia. Poor ventilation and closed-door habitats in an air-conditioned atmosphere during this period could have played a role in human transmission. More research on airquality, population mobility and diseased condition is essential, so that precise proactive measures can be designed to limit the spread of infection in specific climatic seasons. 
1

2 Influence of environmental factors on the spread of COVID-19 in Saudi

3 Arabia

4

5 Syed Mohammed Basheeruddin Asdaq ${ }^{*}$, Syed Imam Rabbani², Abdulhakeem S. Alamri ${ }^{3,4}$,

6 Walaa F. Alsanie ${ }^{3,4}$, Majid Alhomrani ${ }^{3,4}$, Mohammad J. Al-Yamani ${ }^{1}$

7

$8{ }^{1 *}$ Department of Pharmacy Practice, College of Pharmacy, AlMaarefa University, Dariyah,

9 13713, Riyadh, Saudi Arabia, sasdaq@gmail.com

10 2Department of Pharmacology and Toxicology, College of Pharmacy, Qassim University,

11 Buraydah 51452, Kingdom of Saudi Arabia, syedrabbani09@yahoo.com (S.I.R.)

$12{ }^{3}$ Department of Clinical Laboratory Sciences, The Faculty of Applied Medical Sciences, Taif

13 University, Taif, Saudi Arabia, a.alamri@tu.edu.sa (A.S.A), w.alsanie@tu.edu.sa (W.F.A),

14 m.alhomrani@tu.edu.sa (M.A)

$15{ }^{4}$ Centre of Biomedical Sciences Research (CBSR), Deanship of Scientific Research, Taif

16 University, Saudi Arabia

17

18

Corresponding Author:

Prof. Dr. Syed Mohammed Basheeruddin Asdaq,

Department of Pharmacy Practice,

College of Pharmacy,

AlMaarefa University, Dariyah, 13713, Riyadh, Saudi Arabia, sasdag@mcst.edu.sa/sasdaq@gmail.com 


\section{Abstract}

30 Background: Coronavirus disease 2019 (COVID-19) has affected millions of people worldwide.

31 The infection is mostly spread through the inhalation of infected droplets. Saudi Arabia is a vast

32 country having different climatic conditions.

Methods: The study evaluated the influence of environmental factors on the spread of COVID19. Six zones (A to F) were classified depending on the climatic conditions. The study was conducted by retrospective analysis of COVID-19 records from the ministry of health between the months of September 2020 and August 2021. The environmental data such as average temperature $\left({ }^{\circ} \mathrm{C}\right)$, humidity $(\%)$, wind speed $(\mathrm{m} / \mathrm{s})$ and sun exposure $\left(\mathrm{kwh} / \mathrm{m}^{2}\right)$ were retrieved from official sites. The data was analyzed to determine the effect of these factors on the spread of COVID-19. SPSS IBM 25 software was used to conduct the analysis and $p<0.05$ was considered to indicate the significance of the results.

Results: According to the findings, the rate of infection was greater between April and July 2021. Six climatic zones experienced high temperatures, little humidity, consistent wind flow, and intense sun exposure throughout this time. The correlation study revealed a significant $(p<0.05)$ relationship between the environmental factors and the spread of COVID-19. The data suggested that during summer condition when the weather is hot, less humid, and steady wind flow with lots of sun exposure, the COVID-19 infection rate got augmented in Saudi Arabia. Poor ventilation and closed-door habitats in an air-conditioned atmosphere during this period could have played a role in human transmission. More research on air-quality, population mobility and diseased condition is essential, so that precise proactive measures can be designed to limit the spread of infection in specific climatic seasons.

Keywords: Climatic zones, COVID-19, Environmental factors, Saudi Arabia.

\section{Introduction}

Millions of people worldwide were affected by Coronavirus Disease 2019 (COVID-19), which was caused by the severe acute respiratory syndrome coronavirus-2 (SARS-CoV-2). Almost every nation has suffered both economic and human loss due to the spread of the virus. The world health organization declared the infection pandemic and recommended several measures to prevent as well as treat the infection (Rothan and Byrareddy, 2020). The infection normally 
61 presents with symptoms such as fever, cough, and sore throat, and can cause serious 62 complications in patients suffering from respiratory, cardiovascular, and immunity-related co63 morbidities. To date, research at a brisk pace is being conducted to find safe and efficacious 64 preventive and therapeutic interventions for COVID-19 (Zhou., 2020).

65 The major route for person-to-person transmission of COVID-19 is through inhalation of 66 infected air. Infected people's coughs, sneezes, and speech spread the virus and are thought to be 67 the primary causes of infection spread in the community (Bai et al., 2020). The first case of 68 COVID-19 was reported in the Wuhan city of China in December 2019. The virus rapidly spread 69 70 to different countries and the first case in Saudi Arabia was reported in March 2020 (Torales et al., 2020). Several factors have been reported for the spread of COVID-19 in the population. The most important among them is the close contact that can happen at places of work, educational institution, markets, religious and private gatherings (Askitas et al., 2021; Coccia, 2021a). The country imposed several precautionary measures according to the guidelines of world health organization to restrict the spread of the infection (AlKahtani et al., 2021). With over 500,000 confirmed cases as of September 2021, the Kingdom of Saudi Arabia is the second most affected 76 country in the Gulf (Al-Tawfiq and Memish, 2020). Currently, the country is witnessing the second wave and has adopted one of the strictest measures in the region to control the infection (Sanders et al., 2020). Being the largest country in terms of area and population, the reported number of COVID-19 suggests that the government authorities have restricted the spread of infection to a large extent (AlTuraiki et al., 2021).

81 The incubation time for presenting the clinical symptoms is reported to be 2-5 days, and 82 practically during this duration, the infected person can transmit the virus to others. The average time between the onset of symptoms and the onset of disease complications is 14 days (Chan et al., 2020). There are several factors that determine the severity of the disease in the patient. Among them are the load of viral exposure, innate immunity of the host, age, and co-morbid conditions of patients (Linton et al., 2020). Earlier studies indicated that environmental factors could also play a role in the dynamics of COVID-19 transmission (Mofijur et al., 2020; Bashir et al., 2020). Another study suggested that temperatures between $3^{\circ} \mathrm{C}$ and $4^{\circ} \mathrm{C}$ enhanced the transmission rate in the Chinese population (Meo et al., 2020). Low temperature and high humid conditions were also found to favor the infection rate (Zhu and Xin, 2020; Rosario et al., 2020).

91 Other environmental factors such as wind speed, air quality and total sun exposure has positive 
92 effect on the incidences of COVID-19 associated complications (Flexman et al., 2020; 93 Srivastava, 2021; Diao et al., 2021).

94 A study conducted in Saudi Arabia suggested that cold weather supports the survival and 95 multiplication of SARS-CoV-2. Their findings indicated that a decrease in temperature, 96 humidity, and wind speed contributed to elevation of COVID-19 cases in Saudi Arabia 97 (Alkhowailed et al., 2020). However, the report also suggests that unstable temperatures could 98 contribute to the outbreak of COVID-19 (Prata et al., 2020). Additionally, the data from our 99 previous study revealed that the rate of COVID-19 infection was found to have peaked between 100 the months of May and August in Saudi Arabia, when the temperature during this period 101 normally remains very high (Alharbi et al., 2021). Studies conducted to determine the survival of 102 SARS-CoV-2 observed that even at a high temperature $\left(60^{\circ} \mathrm{C}\right)$, the virus can stay alive for 20 103 minutes (van Doremalen et al., 2020). A detailed analysis is essential to determine the influence 104 of environmental factors on the outbreak of COVID-19 in the population.

105 Saudi Arabia is a vast country spread between the Red Sea and the Persian Gulf. It consists of 106 deserts, mountains, valleys, forests, and the ocean. The weather and climatic conditions in 107 different regions of Saudi Arabia varies extremely. In some places the weather is cold and in 108 some it is extremely hot (John and Shaiba, 2021). The intense variation in the climatic condition 109 is reported to be due to uneven land elevation above the sea level (Shaukat et al., 2020). The 110 country has thirteen provinces comprised of major cities, towns, and small villages, and, 111 accordingly, the population is distributed either densely or sparsely in these places (Al112 Bouwarthan et al., 2019). The region experiences frequent dust storms. The extreme weather 113 conditions with dust storms have been reported to contribute as well complicate the respiratory 114 diseases (Coccia, 2021b). These adverse climatic conditions in the previous studies have been 115 reported to be the risk factors for the COVID-19 complications (Ben Matoung et al., 2021). 116 Besides, a significant proportion of population is reported to suffer from the metabolic diseases 117 such as obesity, diabetes mellitus and hypertension. These diseased conditions are also suggested 118 to complicate the COVID-19 (Rahimi et al., 2021).

119 Analyzing the role played by external factors such as weather conditions in the spread of 120 COVID-19 could assist in designing proactive measures for effective control of infection. Hence, 121 this study was planned to investigate the influence of these factors on the infection rate in 122 different climatic zones of Saudi Arabia. 
123

\section{Methods}

\section{Research setting, sample, and data:}

126 Saudi Arabia is a vast country having distinct climatic conditions in different regions and is 127

128

129

130

131

132 133

134

135

136

137

138

139

140

141

142

143

144

145

146

147

148

149

150

151

152

153 mostly due to variation in land elevation. In some places, it is at 0 meters above sea level and in some places as high as 3000 meters. The variation in the elevation of land above sea level has contributed in extreme climatic conditions (John and Shaiba, 2021). After several attempts, a scientific method was adopted to classify the different regions of the country into zones (Figure1). These zones were classified depending on the common climatic conditions that prevail throughout the year such as temperature, wind speed, humidity and sun exposure (Alrasheda and Asif, 2015). This scientific method of classification described in the literature was adopted to categorize the regions into six climatic zones such as:

Zone-A (Hot-dry with maritime): Regions included are Dammam, Dahran, Khobar and Hofuf. Zone-B (Cold-dry with desert): Regions included are Tabuk, Jowf, Arar and Hail.

Zone-C (Hot-dry with desert): Regions included are Riyadh, Buraidah, Madinah and parts of Makkah.

Zone-D (Hot-dry with maritime desert): Regions included are Jeddah, Jizan, Yanbu and parts of Makkah.

Zone-E (Subtropical with Mediterranean and mountains): Regions included are Taif, Abha, Najran and Khamis mushait

Zone-F (Hot-dry desert with empty quarter): Regions included are Abqaiq, Qatif, parts of Ahsa and parts of Hafar Albatein.

The rate of infection reported in the official COVID-19 dashboard was collected. This website is linked to the WHO COVID-19 homepage and reports confirmed COVID-19 cases (both symptomatic and asymptomatic). Detailed information about the number of positive cases detected in different parts of the country was retrieved from the official website of the Saudi Arabian ministry of health (https://Covid19.cdc.gov.sa/daily-updates/). The number of confirmed cases reported daily for each zone was recorded in an excel sheet and then segregated into respective months. A one-year record of the total number of COVID-19 cases detected in different climatic zones of the country was recorded between September 2020 and August 2021. The data on the weather conditions in different regions of the country was collected from the 
154 official website 'National center for meteorology, KSA' (https://www.my.gov.sa/wps/portal).

155 The information such as minimum, maximum, and average recorded temperature $\left({ }^{\circ} \mathrm{C}\right)$, humidity $156(\%)$, wind speed $(\mathrm{m} / \mathrm{s})$ and total sun exposure $\left(\mathrm{kwh} / \mathrm{m}^{2}\right)$ was recorded.

157

158 Measure of variables:

159 The environmental parameters were selected as per the literature by Coccia, 2020a. The data 160 retrieved from the previously mentioned sources were analyzed and represented as:

161 - Normalized infection rate - the total number of COVID-19 infection recorded every month 162 in different climatic zones is normalized (Infection rate = Number of COVID-19 infection / 163 Total population X 10,000) (Yuan et al., 2020) and represented as figure-2.

164

- Mean temperature $\left({ }^{0} \boldsymbol{C}\right)$ - the average temperature measured every month of the climatic 165 zones is represented as figure-3.

- Average humidity (\%) - the mean humidity measured every month in different regions of 167 the climatic zones is represented as figure- 4 .

- Average wind speed $(\mathrm{m} / \mathrm{s})$ - the mean value of wind speed recorded every month in different climatic zones is represented as figure-5.

- Total sun exposure $\left(\boldsymbol{k w h} / \boldsymbol{m}^{2}\right)$ - the average sun exposure recorded from different regions of the climatic zones in every month is represented as figure-6.

173

\section{Data analysis procedure:}

175 The analysis of the data was done as per the methods described by Yuan et al., 2020; Coccia, 176 2021c and Sarkodie and Owusu, 2020. The total number of COVID-19 cases reported in the 177 country was distributed among six climatic zones. The mean weather conditions in different 178 regions of the country were calculated and recorded under respective zones. The COVID-19 and 179 environmental data was represented for each month. The influence of climatic factors such as 180 temperature, humidity, wind speed and total sun exposure on the spread of COVID-19 was 181 analyzed using SPSS-IBM 25 software. Bivariate regression analysis was done between the 182 numbers of COVID-19 cases recorded with the environmental parameters (Figure-7). 183 Differences between the variables were analyzed by using the Chi-square test. Additionally, 184 Spearman's Rho correlation analysis was performed to test the association between the 
185 186 187 188 189 190

191 192

193

194

195

196

197

198

199

200

201

202

203

204

205

206

207

208

209

210

211

212

213

214

215

environmental parameters on COVID-19 (Table-1) (Alkhowailed et al., 2020). The confidence interval was calculated to determine the precision of estimation. $P<0.05$ was used to indicate the significance of results.

\section{Results}

- In the present study, the normalized rate of COVID-19 infection was recorded from September 2020 to August 2021. The data indicated that from September 2020, the rate of infection progressively declined in all the climatic zones. Zone-C (cold dry with desert) was observed to have the maximum infection rate compared to other zones. The decline continued until December 2020 and January 2021, when the infection rate was found to be at its lowest. From February 2021, the infection rate progressively increased in all zones. Upon comparison, Zone-C (cold dry with desert) recorded the rate of infection, followed by Zone-D (hot-dry with maritime desert) and Zone-A (hot-dry maritime). The peak infection rate recorded for each zone is as follows; Zone-A (hot-dry with maritime $)=10.72($ July 2021), Zone-B (cold-dry with desert $)=8.75($ May 2021), Zone-C (hot dry with desert) $=14.19$ (May 2021), Zone-D (hot dry with maritime desert) $=13.28$ (May 2021), Zone-E (subtropical with Mediterranean and mountains) $=9.06$ (June, 2021) and Zone-F (hot dry desert with empty quarter) = 9.75 (June, 2021). The decline from the peak rate was uniform for all zones except Zone B (cold-dry with desert) and Zone-C (hot dry with desert), where a fluctuation in the infection rate was observed in June 2021, and July 2021. Further, all the climatic zones showed a lower infection rate in the month of August 2021 (Figure-2).

- The data on the mean recorded temperature in different climatic zones in a year is represented in figure 3. In the month of September 2020, mild to moderate temperature was recorded in all the zones, and the highest and lowest temperatures were found to be in Zone-D (hot dry with maritime desert) $\left(33.7^{\circ} \mathrm{C}\right.$ ) and Zone-E (subtropical with Mediterranean and mountains) $\left(27.9^{\circ} \mathrm{C}\right)$, respectively. The temperature in the six zones showed progressive reduction reaching lowest in the month of January 2021. The lowest 
216

217

218

219

220

221

222

223

224

225

226

227

228

229

230

231

232

233

234

235

236

237

238

239

240

241

242

243

244

245

246

247

recorded temperature in the month of January 2020 for each zone is as follows; Zone-A (hot dry with maritime) $=14.8{ }^{\circ} \mathrm{C}$, Zone-B (cold dry with desert) $=11.2{ }^{\circ} \mathrm{C}$, Zone-C (hot dry with desert) $=12.6{ }^{\circ} \mathrm{C}$, Zone-D (hot dry with maritime desert) $=26.5^{\circ} \mathrm{C}$, Zone-E (subtropical with Mediterranean and mountains) $=15.5{ }^{\circ} \mathrm{C}$ and Zone-F (hot dry desert with empty quarter) $=16.3{ }^{\circ} \mathrm{C}$. From February 2021 the temperature in all the zones increased progressively and reached the peak in the month of August, 2021. The highest recorded temperature in the month of August 2021 is Zone-A (hot dry with maritime) $=36.1^{\circ} \mathrm{C}$, Zone-B (cold dry with desert) $=34.6^{\circ} \mathrm{C}$, Zone-C (hot dry with desert $)=34.9^{\circ} \mathrm{C}$, Zone-D (hot dry with maritime desert) $=35.6{ }^{\circ} \mathrm{C}$, Zone-E (subtropical with Mediterranean and mountains) $=29.6^{\circ} \mathrm{C}$ and Zone-F (hot dry desert with empty quarter) $=39.5^{\circ} \mathrm{C}$.

- The record of humidity in different climatic zones of Saudi Arabia indicates that in the month of September 2020 the highest percentage of humidity was observed in the ZoneD (hot dry with maritime desert), while other zones recorded below $40 \%$. The level of humidity progressively increased from September 2020 in all the zones, except in ZoneD (hot dry with maritime desert) where it showed slow decline. The highest level of humidity for Zone-A (hot dry with maritime) was recorded in January, 2021 (59\%), Zone-B (cold dry with desert) in January, 2021 (57\%), Zone-C (hot dry with desert) in December, 2020 (51\%), Zone-D (hot dry with maritime desert) in September, 2021 (67\%), Zone-E (subtropical with Mediterranean and mountains) in December, 2020 and January, 2021 (60\%) and Zone-F (hot dry desert with empty quarter) in January, 2021 (54\%). After reaching peak in January 2021, the percentage of humidity started to decline progressively in all zones. The lowest humidity level was recorded for Zone-C (hot dry with desert) (12\%) in January 2021. The record of Zone-D (hot dry with maritime desert) indicated less fluctuation and remained steady in all months (Figure-4).

- The data for wind speed in different climatic regions is represented in figure 5. In the month of September 2020, the highest wind speed was recorded for Zone-A (hot dry with maritime) $(3.7 \mathrm{~m} / \mathrm{s})$. The wind speed for other zones ranged between 1.7 to $2.3 \mathrm{~m} / \mathrm{s}$ in the month of September 2020. The wind speed for Zone-A (hot dry with maritime) showed a 
248

249

250

251

252

253

254

255

256

257

258

259

260

261

262

263

264

265

266

267

268

269

270

271

272

273

274

275

276

277

278

279

higher level of fluctuation and the peak for this zone was found in April $2021(5.8 \mathrm{~m} / \mathrm{s})$. The zone-B (cold dry with desert) $(5.2 \mathrm{~m} / \mathrm{s})$ and Zone-C (hot dry with desert) $(2.8 \mathrm{~m} / \mathrm{s})$ recorded the highest wind speed in the month of June 2021. Zone-D (hot dry with maritime desert) experienced the highest wind speed in the month of February 2021 (2.6 $\mathrm{m} / \mathrm{s}$ ) and March 2021 (2.5 m/s). Zone-E (subtropical with Mediterranean and mountains) $(2.8 \mathrm{~m} / \mathrm{s})$ and Zone-F (hot dry desert with empty quarter) $(3.1 \mathrm{~m} / \mathrm{s})$ recorded their peak wind speed in the month of January 2021.

- The total sun exposure for the different climatic zones can be found in figure 6 . According to the data available, Zone-B (cold dry with desert) recorded the highest sun exposure followed by Zone-D (hot dry with maritime desert). The least sun exposure was found to be in Zone-E (subtropical with Mediterranean and mountains). The quantum of sun exposure in different zones of climate are Zone-A (hot dry with maritime) (2000$2050 \mathrm{kwh} / \mathrm{m}^{2}$ ), Zone-B (cold dry with desert) (2300-2400 kwh/m²), Zone-C (hot dry with desert) (2100-2150 kwh/m²), Zone-D (hot dry with maritime desert) (2150-2200 $\mathrm{kwh} / \mathrm{m}^{2}$ ), Zone-E (subtropical with Mediterranean and mountains) (1900-1950 kwh/m²) and Zone-F (hot dry with empty quarter) $\left(2050-2150 \mathrm{kwh} / \mathrm{m}^{2}\right)$. 
280

281

282

283

284

285

286

287

288

289

290

291

292

293

\section{Discussion}

295

296

297

298

299

300

301

302

303

304

305

306

307

308

309

310

and significant correlation $(\mathrm{Rho}=-0.188, p<0.05)$ for Zone-F (hot dry desert with empty quarter). Other zones although suggested both positive and negative correlations but were found to be non-significant. The data for humidity parameter suggested a significant and positive correlation for Zone-A (hot dry with maritime) $(\mathrm{Rho}=0.388, p<0.01)$ and Zone-D (hot dry with maritime desert) (Rho $=0.044, p<0.05$ ). However, data of other zones did not suggested similarity in correlation. The wind speed data analysis suggested a positive and significant $(\mathrm{Rho}=0.276, p<0.05)$ correlation for only Zone-C (hot dry with desert), while other zones were found to be insignificantly correlated. Analysis of the data recorded for total sun exposure in different climatic zones revealed a negative and significant association for Zone-B (cold dry with desert) ( $\mathrm{Rho}=-0.170, p<0.05)$ and ZoneE (subtropical with Mediterranean and mountains) $(\mathrm{Rho}=-0.172, p<0.05)$, whereas other climatic zones indicated non-significant correlation.

Saudi Arabia is a large country and has an area of 2.3 million square kilometers. The climatic condition of the country varies from region to region and is mainly due to land elevations that range from 0 to 3000 meters above the average sea level. According to climatic conditions, the regions of the country are scientifically classified into six zones (Alrasheda and Asif, 2015). The weather varies greatly in these zones, from hot to cold, humid to dry, forest to desert, green lands to empty valleys. Most places receive infrequent rainfall and there is no permanent river (Figure1). Water requirements are met through desalination of sea water and, to some extent, underground water (Tarawneh and Chowdhury, 2018).

The present study evaluated the influence of environmental parameters on the spread of COVID19. The normalized infection rate in Zone-A (hot dry with maritime) started to show a progressive decline from the month of September 2020 and reached its lowest number in December 2020. During this month, the temperature showed a decline, the humidity increased and wind speed slightly fluctuated (Figure-2 to 5). And from January 2021, the number of COVID-19 cases increased every month and reached its maximum in May 2021. The weather conditions during this period showed an increase in temperature, a decrease in humidity, and an increase in wind speed (Figure-2 to 5). Zone-A (hot dry with maritime) includes the regions 
311 comprised of Dammam, Dahran, Khobar and Hofuf (Almazroui et al., 2012). These places are in

312 hot-dry maritime areas with $2000-2020 \mathrm{kwh} / \mathrm{m}^{2}$ annual sun exposure (Figure-6) and have mostly

313 oil and gas refinery occupations. The correlation analysis indicated that the level of humidity 314 (Rho=0.388, $p<0.01)$ positively influenced the spread of COVID-19 (Table-1). These findings 315 are in accordance with the previous research that suggested a humid atmosphere supports SARS316 CoV-2 survival (Alkhowailed et al., 2020; Zhu and Xin, 2020; Rosario et al., 2020). Studies 317 suggest that younger generations have higher chances of infection due to their negligence 318 attitude and reluctance to follow precautionary measures (Zhou et al., 2020).

319 Data analysis for the climatic Zone-B (cold dry with desert) indicated the lowest COVID-19 320 infection rate in December 2020 and the corresponding temperature recorded was found to be the 321 lowest $\left(12.1^{\circ} \mathrm{C}\right)$, humidity increased to $53 \%$, and wind speed was steady. The highest infection 322 was observed in July 2021, and the temperature in this month increased to $33.4{ }^{\circ} \mathrm{C}$, with a 323 reduced level of humidity $(15 \%)$ and moderate wind speed $(2.6 \mathrm{~m} / \mathrm{s})$ (Figure-2 to 5). The regions 324 covered under this climatic zone are Tabuk, Jawf, Arar and Hail. These places have cold, dry 325 weather and are mainly covered with deserts (Almazroui et al., 2012). The correlation analysis 326 indicated a negative and significant $(\mathrm{Rho}=-0.170, p<0.05)$ association between sun exposure and

327 328 329 330 331 332 333 334 335 336 337 338 339 340 341 COVID-19 spread (Table-1). This zone was found to receive the maximum amount of total sun exposure (2300-2400 kwh/m²) (Figure-6). Being in a region of extreme cold and hot weather, the reduced exposure to sunlight might have contributed to COVID-19 (Ratnesar-Shumate et al., 2020). Previous studies have indicated that exposure to sun light is essential for the synthesis of vitamin D and for immune activity (Grant et al., 2020). Inadequate levels of vitamin D were observed in hospitalized patients due to COVID-19 (Radujkovic et al., 2020).

In Zone-C (hot dry with desert), the lowest COVID-19 infection rate was recorded in December 2020 , and the temperature was found to be reduced to $15.4^{\circ} \mathrm{C}$, with increased humidity $(51 \%)$ and steady wind speed $(2.1 \mathrm{~m} / \mathrm{s})$. The highest recorded infection was in June 2021. The temperature in this month increased to $34.7{ }^{\circ} \mathrm{C}$, with reduced humidity (12\%) and slightly enhanced wind speed $(2.6 \mathrm{~m} / \mathrm{s})$ (Figure-2 to 5). The zone covers the central parts of the country, comprising the hot-dry deserts of Riyadh, Buraidah, Madinah, and parts of Makkah (Almazroui et al., 2012). These regions receive total sun exposure of $2100-2150 \mathrm{kwh} / \mathrm{m}^{2}$ (Figure-6) and rainfall rarely occurs in a year. The correlation analysis indicated a positive and significant association of wind speed $(\mathrm{Rho}=0.276, p<0.05)$ on COVID-19 (Table-1). As the meteorological 
342 data indicated a steady wind flow, the infection might have remained in the atmosphere for a

343 longer duration and contributed to a higher rate of transmission due to the high density of the

344 population in this region. Studies in the past have also suggested low wind flow especially in the

345 densely populated regions enhanced the infection rate (Coccia, 2020b). In addition, high humid

346 conditions and dust storms frequently seen in these regions can augment the pathogenesis of

347 COVID-19 (Coccia, 2021d). Further, dense human population itself can trigger higher 348 transmission of COVID-19 (Rostami et al., 2021; Xu et al., 2020). Polluted air with presence of

349 several toxic chemicals can affect the health of the population and can increase the chances of 350 COVID-19 infection (Sarkodie and Owusu, 2020). Together, it can be suggested that higher 351 population density and mobility with poor air-quality of the region might have influenced the 352 COVID-19 infection rate in this zone (Shen et al., 2021). Similar studies in other parts of world 353 also suggested that the population density, pollution and poor air-quality have enhanced the 354 COVID-19 infection rate (Xu et al., 2020; Yuan et al., 2020).

355 The climatic Zone-D (hot dry with maritime desert) recorded the highest and lowest COVID-19 356 infection rate in the month of January 2021 and May 2021, respectively. The corresponding 357 temperature was found to be slightly reduced $\left(26.5^{\circ} \mathrm{C}\right)$ and increased $\left(32.1^{\circ} \mathrm{C}\right)$, while humidity 358 decreased (60\%) and then became constant (56\%) with steady wind speed during these periods

359 (Figure-2 to 5). This climatic zone is known for its hot-dry weather with maritime influences and 360 includes cities located on the coast of the Red Sea such as Jeddah, Jizan, Yanbu, and some parts 361 of the Makkah region (Almazroui et al., 2012). The area receives an annual sun exposure of $3622150-2200 \mathrm{kwh} / \mathrm{m}^{2}$ (Figure-6). The association between the environmental factors indicated a 363 positive and significant $(\mathrm{Rho}=0.044, p<0.05)$ correlation between humidity and COVID-19 364 (Table-1). As the humidity level in this zone remains at a constant level for most of the year, it 365 could have provided a suitable environment for the survival and pathogenesis of COVID-19 366 (Alkhowailed et al., 2020; Islam et al., 2021).

367 Analysis of data for Zone-E (subtropical with Mediterranean and mountains) suggested that the 368 lowest recorded COVID-19 infection rate was in December 2021, and the corresponding weather 369 conditions were a drop in temperature $\left(16.5^{\circ} \mathrm{C}\right)$, increased humidity $(61 \%)$ and steady wind flow $370(2 \mathrm{~m} / \mathrm{s})$. The highest rate of infection was observed in July 2021, with an increased temperature $371\left(29.1{ }^{\circ} \mathrm{C}\right)$, decreased humidity $(25 \%)$ and enhanced wind speed $(2.8 \mathrm{~m} / \mathrm{s})$ (Figure-2 to 5). The 372 zone is comprised of high-altitude places with mountains, pleasant weather, water bodies, and 
373 greenery. The regions covered are Taif, Abha, Najran, and Khamis Mushait, which are popular 374 tourist spots (Almazroui et al., 2012). The sun exposure was found to be lowest in this zone $375\left(1900-1950 \mathrm{kwh} / \mathrm{m}^{2}\right)$ (Figure-6). The correlation analysis suggested a positive and significant 376 association of temperature $(\mathrm{Rho}=0.118, p<0.05)$, and a negative and significant association of

377 378 379 380 381 382 383

384 385 386 387 388 389 390 391

392 393 394 395 396 397 398 399 400 401 402 sun exposure $(\mathrm{Rho}=-0.172, p<0.05)$ with COVID-19 spread (Table-1). Earlier studies have suggested that temperature and exposure to sun rays could contribute to the reduction of COVID19 pathogenesis (Alkhowailed et al., 2020; Grant et al., 2020). The weather conditions of the region are pleasant with low levels of sun exposure, which might have provided the optimal environment for the multiplication of COVID-19 (Almazroui et al., 2012). Being a tourist place, the region could have enhanced the transmission of the infection from one part of the country to another (Askitas et al., 2021).

The data obtained from Zone-F (hot dry desert with empty quarter) indicated the lowest and highest COVID-19 infection rate in January 2021 and June 2021, respectively. Corresponding weather data was temperature decreased in December $2020\left(16.3^{\circ} \mathrm{C}\right)$ and increased in June, 2021 $\left(34.8{ }^{\circ} \mathrm{C}\right)$, humidity increased (54\%) and then decreased (38\%) and wind speed was $2.1 \mathrm{~m} / \mathrm{s}$ in December, 2020 and $3.1 \mathrm{~m} / \mathrm{s}$ in January, 2021 (Figure-2 to 5). This climatic zone is known as the "empty zone" as the human habitat is sparingly distributed in the vast areas of deserts. The regions covered under this area are Abqaiq, Qatif, parts of Ahsa and parts of Hafar Albatein (Almazroui et al., 2012). The total sun exposure received here was $2050-2150 \mathrm{kwh} / \mathrm{m}^{2}$ (Figure$6)$. The correlation analysis suggested a negative and significant association between temperature (Rho=-0.188, $p<0.05$ ) for the COVID-19 (Table-1). The region is comprised of deserts with extreme temperatures that might have contributed to most of the indoor activities with a closed atmosphere, leading to the spread of COVID-19 (Alkhowailed et al., 2020; and Grant et al., 2020).

97 Overall, the data from the present study indicated that the rate of infection increased in all the climatic zones when the weather becomes hot, less humid, and steady wind flow. Temperature is one of the important characteristics that is reported to directly influence the immune activity of the host system (Alkhowailed et al., 2020). Extreme temperature conditions (both cold and hot) are known to support microbial infections (Alkhowailed et al., 2020 and Ahmadi et al., 2020). However, our data suggested that at lower temperatures, the infection rate declined, and as the 
403 temperature increased, the infection rate also increased (Figure-2 and 3). One reason for this 404 could be the closed-door activities preferred during the summer season in this region.

405 The major portion of Saudi Arabia is reported to experience a peak temperature between the 406 months of May and August every year (Haque and Rahman, 2020). Further, the lower humidity 407 level experienced during this period (Figure-4) prevents ventilation and makes it uncomfortable 408 to venture out in scorching heat. During this period, the population prefers to stay and work in a 409 closed-door atmosphere. The use of air-conditioning has also become routine during this season, 410 preventing ventilation, and contributing to a higher transmission rate of COVID-19 (Rule, 2020). 411 Further, wind speed in most of the climatic zone was found to be steady except in coastal zones 412 such as Zone-A (hot dry with maritime) and part of Zone-B (cold dry with desert) (Figure-5). 413 Slightly more than average wind speed during the months of May-August (Figure-5) might have 414 augmented the chances of transmission when people in the evening ventured out of their 415 residences.

416 According to the literature, the amount of sun exposure is directly responsible for the 417 antimicrobial activity. The powerful rays from the sun, such as ultraviolet, can cause damage to 418 microbial cell walls, decreasing the chance of infection (Grant et al., 2020). The data from the 419 study indicated that most of the country received an above-normal exposure to the sun, and this 420 can be seen in most parts of the year (Figure-6). However, the maximum sun exposure was found 421 to be during the summer season when the days are long and hot. The summer in Saudi Arabia is 422 extreme in most places except in Zone-E (subtropical with Mediterranean and mountains) 423 (Almazroui et al., 2012). Since a major proportion of the population avoids sun exposure during 424 summer, this might have prevented the chances of the virus being killed due to sun light and the 425 preference to stay indoors might have increased the transmission rate in summer (Rule, 2020; 426 Coccoa, 2020c). The bivariate analysis also indicated the correlation of environmental factors 427 such as temperature, humidity, wind speed, and sun exposure on the COVID-19 transmission 428 between the months of peak summer such as April 2021, and July 2021 (Figure-7).

429 The decline in the COVID-19 infection from the month of August 2021 could be related to 430 several factors. Saudi Arabia is known to have implemented one of the strictest precautionary 431 measures such as wearing of face marks, social distancing, preventing crowding in public places 432 and avoiding social gatherings (AlKahtani et al., 2021). The country is providing free COVID-19 433 immunization for people above 12 years age. The vaccination program started from the 
434 beginning of 2021 and has achieved herd immunity in October 2021 in all regions of climatic 435 zones. The health authorities of the country were reported to follow updated guidelines for 436 preventing and treating the COVID-19 infection AlTuraiki et al., 2021). These factors could also 437 be the reason for decline in the infection.

438 The observations of the present study have provided a preliminary data on the spread of COVID43919 in six climatic zones of Saudi Arabia. Although, biological characteristics of the SARS-CoV4402 does not change between regions but its transmission and infection rate are reported to get 441 influenced by the environmental and population-based factors (Coccia, 2021e). In the absence of 442 substantial evidence to link the role of specific environmental factor, more studies are suggested 443 with an aim to determine the role of air-quality, population mobility and diseased conditions of 444 the population on the COVID-19 spread (Coccia, 2021f).

\section{Conclusions}

448 The current research examined the environmental factors that would have influenced the spread 449 of COVID-19 in Saudi Arabia's six climatic zones. According to the data, humid conditions in

450

451

452

453

454

455

456

457

458

459

460

461

462

463

464

465 maritime zones, high temperature in hot-dry zones, inadequate sun exposure in cold-dry zones and tourist activities in subtropical zones might have influenced the COVID-19 infection rate. All the zones experienced peak infection rate between the months April 2021 and July 2021 that corresponds to summer condition in the country. Close-door activities in hot-dry places, insufficient ventilation in humid regions, inadequate sun exposure in cold-dry areas and movements of travelers in the subtropical Mediterranean quarters might have augmented the transmission rate of COVID-19 infection. The healthcare authorities and public can have a look on these aspects and can design suitable strategies to avoid close-door activities, improve the ventilation, increase the sun exposure and restrict the vocational events to prevent the next wave of pandemic in their regions of habitats. In the absence of specific link between other factors such as role of air-quality, diseased states and population mobility, more research is suggested in this direction to determine their influence on the rate of COVID-19 infection. 


\section{References}

467

468

469

470

471

472

473

474

475

476

477

478

479

480

481

482

483

484

485

486

487

488

489

490

491

492

493

494

495

496

1. Ahmadi, M., Sharifi, A., Dorosti, S., Ghoushchi, S.J., Ghanbari, N. 2020. Investigation of effective climatology parameters on COVID-19 outbreak in Iran. Sci. Total Environ., $729,138705$.

2. Al-Bouwarthan, M., Quinn, M.M., Kriebel, D., Wegman, D.H. 2019. Assessment of Heat Stress Exposure among Construction Workers in the Hot Desert Climate of Saudi Arabia. Ann. Work Expo. Health. 63(5), 505-520.

3. Alharbi, M.M., Rabbani, S.I., Asdaq, S.M.B., Alamri, A.S., Alsanie,W.F. 2021. Infection Spread, Recovery, and Fatality from Coronavirus in Different Provinces of Saudi Arabia. Healthcare. 9, 931-43.

4. Alkahtani, T.A., Alakeel, A., Alakeel, R.A., Khorshid, F.A., Alshammari, H.H., Alguwaihes, A.M., Almohideb, M., Ali, E.M., Bin-Jumah, M., Abdel-Daim, M.M., Jammah, A.A. 2021. The current reproduction number of COVID-19 in Saudi Arabia: is the disease controlled? Environ Sci Pollut Res Int. 28, 44812-44817.

5. Alkhowailed, M., Shariq, A., Alqossayir, F., Alzahrani, O.A., Rasheed, Z., Aladulmomem, W. 2020. Impact of meteorological parameters on COVID-19 pandemic: A comprehensive study from Saudi Arabia. Infor. Med. Unlocked. 20, 100418.

6. Almazroui, M., Nazrul Islam, M., Athar, H., Jones, P.D., Rahman, M.A. 2012. Recent climate change in the Arabian Peninsula: annual rainfall and temperature analysis of Saudi Arabia for 1978-2009. Int. J. Climatology. 32, 953-966.

7. Alrasheda, F and Asif, M. 2015. Climatic classifications of Saudi Arabia for building energy Modelling. Energy Procedia. 75, 1425 - 1430.

8. Al-Tawfiq, J.A., Memish, Z.A. 2020. COVID-19 in the Eastern Mediterranean Region andSaudi Arabia: prevention and therapeutic strategies. Int. J. Antimicrob Agents. 105968, 22-9.

9. Al-Turaiki, I., Almutlaq, F., Alrasheed, H., Alballa, N. 2021. Empirical evaluation of alternative time-series models for covid-19 forecasting in Saudi Arabia, International J Environ. Res. Public Health 18(16), 8660.

10. Askitas, N., Tatsiramos, K., Verheyden, B. 2021. Estimating worldwide effects of nonpharmaceutical interventions on COVID-19 incidence and population mobility patterns using a multiple-event study. Sci. Rep. 11, 1972. 
497

498

499

500

501

502

503

504

505

506

507

508

509

510

511

512

513

514

515

516

517

518

519

520

521

522

523

524

525

526

11. Bai, Y., Yao, L., Wei, T., Tian, F., Jin, D., Chen, L. 2020. Presumed Asymptomatic Carrier Transmission of COVID-19. JAMA. 323(14), 1406.

12. Bashir, M.F., Bilal, B.M., Komal, B., 2020. Correlation between environmental pollution indicators and COVID-19 pandemic: A brief study in Californian context. Environ. Res. $187,109652$.

13. Ben Maatoug, A., Triki, M.B., Fazel, H. 2021. How do air pollution and meteorological parameters contribute to the spread of COVID-19 in Saudi Arabia? Environ Sci Pollut Res Int. 28(32), 44132-44139.

14. Chan, J., Yuan, S., Kok, K., To, K., Chu, H., Yang, J., Xing, F., Liu, J., Yip C. 2020. A familial cluster of pneumonia associated with the 2019 novel coronavirus indicating person-to-person transmission: A study of a family cluster. Lancet. 395, 514-523.

15. Coccia M. 2020a. How (Un)sustainable Environments are Related to the Diffusion of COVID-19: The Relation between Coronavirus Disease 2019, Air Pollution, Wind Resource and Energy. Sustainability. 12, 9709.

16. Coccia M. 2020b. An index to quantify environmental risk of exposure to future epidemics of the COVID-19 and similar viral agents: Theory and Practice. Environ. Res. $191,110155$.

17. Coccia M. 2020c. Factors determining the diffusion of COVID-19 and suggested strategy to prevent future accelerated viral infectivity similar to COVID. Sci Total Environ. 729, 138474.

18. Coccia M. 2021a. The impact of first and second wave of the COVID-19 pandemic: comparative analysis to support control measures to cope with negative effects of future infectious diseases in society. Environ Res. 197, 111099.

19. Coccia M. 2021b. Effects of the spread of COVID-19 on public health of polluted cities: results of the first wave for explaining the dejà vu in the second wave of COVID-19 pandemic and epidemics of future vital agents. Environ Sci Pollut Res Int. 28(15), 1914719154.

20. Coccia M. 2021c. The effects of atmospheric stability with low wind speed and of air pollution on the accelerated transmission dynamics of COVID-19. Int. J. Environ. Studies. 78:1, 1-27., 
527

528

529

530

531

532

533

534

535

536

537

538

539

540

541

542

543

544

545

546

547

548

549

550

551

552

553

554

555

556

557

21. Coccia M. 2021d. Preparedness of countries to face covid-19 pandemic crisis: Strategic positioning and underlying structural factors to support strategies of prevention of pandemic threats. Environ Res. 203, 111678

22. Coccia M. 2021e. Pandemic Prevention: Lessons from COVID-19. Encyclopedia of COVID-19. 1, 433-444.

23. Coccia M. 2021f. High health expenditures and low exposure of population to air pollution as critical factors that can reduce fatality rate in COVID-19 pandemic crisis: a global analysis. Environ Res. 199, 111339

24. Diao, Y., Kodera, S., Anzai, D., Gomez-Tames, J., Rashed, E.A., Hirata, A. 2020. Influence of population density, temperature, and absolute humidity on spread and decay durations of COVID-19: A comparative study of scenarios in China, England, Germany, and Japan. One Health. 12, 100203.

25. Flaxman, S., Mishra, S., Gandy, A., Unwin, H.J.T., Mellan, T.A., Coupland, H., Whittaker, C., Bhatt, S. 2020. Estimating the effects of non-pharmaceutical interventions on COVID-19 in Europe. Nature. 584, 257-261.

26. Grant, W.B., Lahore, H., McDonnell, S.L., Baggerly, C.A., French, C.B., Aliano, J.L., Bhattoa, H.P. 2020. Evidence that Vitamin D Supplementation Could Reduce Risk of Influenza and COVID-19 Infections and Deaths. Nutrients. 12(4), 988.

27. Haque, S.E., Rahman, M. 2020. Association between temperature, humidity, and COVID-19 outbreaks in Bangladesh. Environ. Sci. Policy. 114, 253-255

28. Islam, N., Bukhari, Q., Jameel, Y., Massaro, J.M., D'Agostino, R.B. 2021. COVID-19 and climatic factors: A global analysis. Environ. Res. 193,110355

29. John, M., Shaiba, H. 2021. Correlation between weather and COVID-19 cases: An extensive study covering all provinces in Saudi Arabia.International Conference of Women in Data Science at Taif University, 9430202.

30. Linton, N., Kobayashi, T., Yang, Y., Hayashi, K., Akhmetzhanov, A., Jung, S. 2020. Incubation Period and Other Epidemiological Characteristics of 2019 Novel Coronavirus Infections with Right Truncation: A Statistical Analysis of Publicly Available Case Data. J. Clin. Med. 9(2), 538-542.

31. Meo, S., Abukhalaf, A., Alomar, A., Al-Beeshi, I., Alhowikan, A., Shafi, K. 2020. Climate and COVID-19 pandemic: effect of heat and humidity on the incidence and 
558

559

560

561

562

563

564

565

566

567

568

569

570

571

572

573

574

575

576

577

578

579

580

581

582

583

584

585

586

mortality in world's top ten hottest and top ten coldest countries. Eur. Rev. Med. Pharmacol. Sci., 24, 8232-8238.

32. Mofijur, M., Rizwanul, F.I., Saiful-Islam, A., Uddin, M., Ashrafur-Rahman, S., Chowdhury, M. 2020. Relationship between Weather Variables and New Daily Covid-19 Cases in Dhaka, Bangladesh, Sustainability. 12, 8319-8324.

33. Prata, D.N., Rodrigues, W., Bermejo, P.H. 2020. Temperature significantly changes COVID-19 transmission in (sub) tropical cities of Brazil. Sci. Total Environ., 729, 138862.

34. Radujkovic, A., Hippchen, T., Tiwari-Heckler, S., Dreher, S., Boxberger, M., Merle, U. 2020. Vitamin D Deficiency and Outcome of COVID-19 Patients. Nutrients. 12(9), 2757.

35. Rahimi, N.R., Fouladi-Fard, R., Aali, R., Gea, O., Fiore, M. 2021. Bidirectional association between COVID-19 and the environment: A systematic review. Environ. Res. 194, 110692

36. Ratnesar-Shumate, S., Williams, G., Green, B., Krause, M., Holland, B., Wood, S., Bohannon, J., Boydston, J., Freeburger, D., Hooper, I. 2020. Simulated sunlight rapidly inactivates SARS-CoV-2 on surfaces. J. Infect. Dis., 222, 214-222.

37. Rosario Denes, K.A., Mutz Yhan, S., Bernardes Patricia, C., Conte-Junior Carlos, A., 2020. Relationship between COVID-19 and weather: case study in a tropical country. Int. J. Hyg. Environ. Health. 229, 113587.

38. Rostami, A., Sepidarkish, M., Leeflang, M.M.G., Riahi, S.M., Nourollahpour., Shiadeh, M., Esfandyari, S., Mokdad, A.H., Hotez, P.J., Gasser, R.B. 2021. SARS-CoV-2 seroprevalence worldwide: a systematic review and meta-analysis. Clin. Microbiol. Infect. 27, 331-340.

39. Rothan, H., Byrareddy, S. 2020. The epidemiology and pathogenesis of coronavirus disease (COVID-19) outbreak. J. Autoimmunity. 109,102433.

40. Rule AM. 2020. COVID-19 Outbreak Associated with Air Conditioning in Restaurant, Guangzhou, China, 2020. Emerg. Infect. Dis., 26, 2791.

41. Sanders, J., Monogue, M., Jodlowski, T. 2020. Cutrell J. Pharmacologic Treatments for Coronavirus Disease 2019 (COVID-19). JAMA. 18, 1824-37. 
587

588

589

590

591

592

593

594

595

596

597

598

599

600

601

602

603

604

605

606

607

608

609

610

611

612

613

614

615

616

42. Sarkodie, S.A., Owusu, P.A. 2020. Impact of meteorological factors on COVID-19 pandemic: Evidence from top 20 countries with confirmed cases. Environ. Res. 191, 110101

43. Shaukat, M.H., Al-Dousari, A., Hussain, I., Faisal, M., Ismail, M., Mohamd Shoukry, A., Elashkar, E.E., Gani, S. 2020. Evaluation of wet and dry event's trend and instability based on the meteorological drought index. PeerJ., 8, e9729.

44. Shen, L., Zhao, T., Wang, H., (...), Zhu, Y., Shu, Z. 2021. Importance of meteorology in air pollution events during the city lockdown for COVID-19 in Hubei Province, Central China. Sci Total Environ. 754, 142227.

45. Srivastava, A. 2021. COVID-19 and air pollution and meteorology-an intricate relationship: A review, Chemosphere, 263,128297

46. Tarawneh, Q and Chowdhury, S. 2018. Trends of climate change in Saudi Arabia: Implications on water resources. Climate. 6, 1-9

47. Torales, J., O'Higgins, M., Castaldelli-Maia, J., Ventriglio, A. 2020. The outbreak of COVID-19 coronavirus and its impact on global mental health. Int. J. Soc. Psychiary., 66(4), 317-320.

48. van Doremalen, N., Bushmaker, T., Morris, D.H., Holbrook, M.G., Gamble, A., Williamson, B.N., Tamin, A., Harcourt, J.L., Thornburg, N.J., Gerber, S.I., Lloyd-Smith, J.O., de Wit, E., Munster, V.J. 2020. Aerosol and Surface Stability of SARS-CoV-2 as Compared with SARS-CoV-1. N Engl J Med., 382(16), 1564-1567.

49. Weather information of Saudi Arabia. 2021. Available from: https://www.my.gov.sa/wps/portal/snp/aboutksa/geospatialandgeographicinformation\#he ader 24

50. Xu K, Cui K, Young L-H, Hsieh Y-K, Wang Y-F, Zhang J. 2020. Impact of the COVID19 Event on Air Quality in Central China. Aerosol and Air Quality Res. 20, 915-929.

51. Yuan, J., Li, M., Lv, G., Lu, Z.K. 2020. Monitoring transmissibility and mortality of COVID-19 in Europe. Int. J. Infect. Dis., 95, 311-315.

52. Zhou, F., Yu, T., Du, R., Fan, G., Liu, Y., Liu, Z. 2020. Clinical course and risk factorsfor mortality of adult inpatients with COVID-19 in Wuhan, China: a retrospective cohort study. Lancet 395, 1054-62. 
617 53. Zhou, P. 2020. A pneumonia outbreak associated with a new coronavirus of probable bat 618

619

620 origin. Nature. 579, 1-4.

621

54. Zhu Y., Xin J. 2020. Association between ambient temperature and COVID-19 infection in 122 cities from China. Sci Total Environ. 724, 138201. 


\section{Table $\mathbf{1}$ (on next page)}

Table-1: Summary of correlation analysis between COVID-19 and environmental parameters.

Statistics: Spearman's correlation test. ${ }^{*} p<0.05,{ }^{* *} p<0.01$ 
Table-1: Summary of correlation analysis between COVID-19 and environmental

2 parameters.

\begin{tabular}{|c|c|c|c|c|}
\hline $\begin{array}{c}\text { Geographical } \\
\text { distribution }\end{array}$ & $\begin{array}{c}\text { Temperature } \\
\text { (Rho value) }\end{array}$ & $\begin{array}{c}\text { Humidity } \\
\text { (Rho value) }\end{array}$ & $\begin{array}{c}\text { Wind speed } \\
\text { (Rho value) }\end{array}$ & $\begin{array}{c}\text { Sun exposure } \\
\text { (Rho value) }\end{array}$ \\
\hline Zone A & -0.136 & $0.388^{* *}$ & -0.92 & -0.201 \\
\hline Zone B & 0.052 & -0.132 & -0.234 & $-0.170^{*}$ \\
\hline Zone C & -0.082 & -0.267 & $0.276^{*}$ & -0.046 \\
\hline Zone D & -0.159 & $0.044^{*}$ & -0.071 & -0.336 \\
\hline Zone E & $0.118^{*}$ & 0.164 & 0.162 & $-0.172^{*}$ \\
\hline Zone F & $-0.188^{*}$ & -0.074 & -0.106 & -0.149 \\
\hline
\end{tabular}

Statistics: Spearman's correlation test. ${ }^{*} p<0.05,{ }^{* *} p<0.01$ 
Figure 1

Figure-1: Climatic zones of Saudi Arabia 


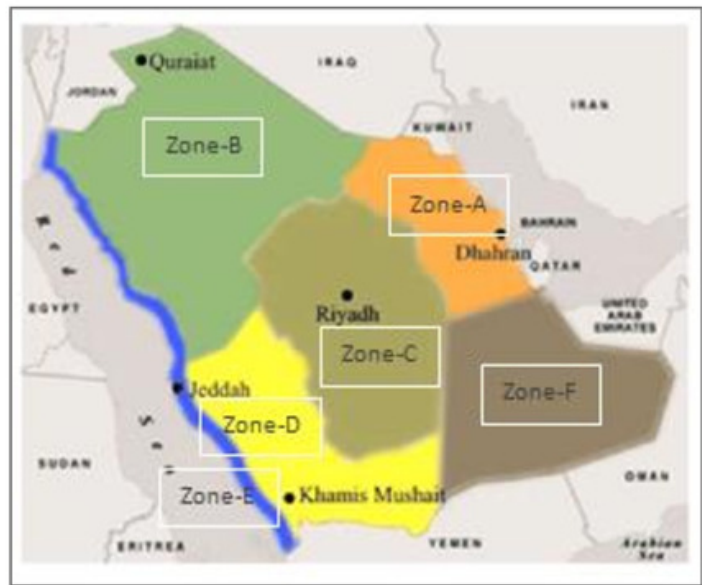

Figure-1: Climatic zones of Saudi Arabia. 
Figure 2

Figure-2: Normalized COVID-19 infection rate in different climatic zones. 


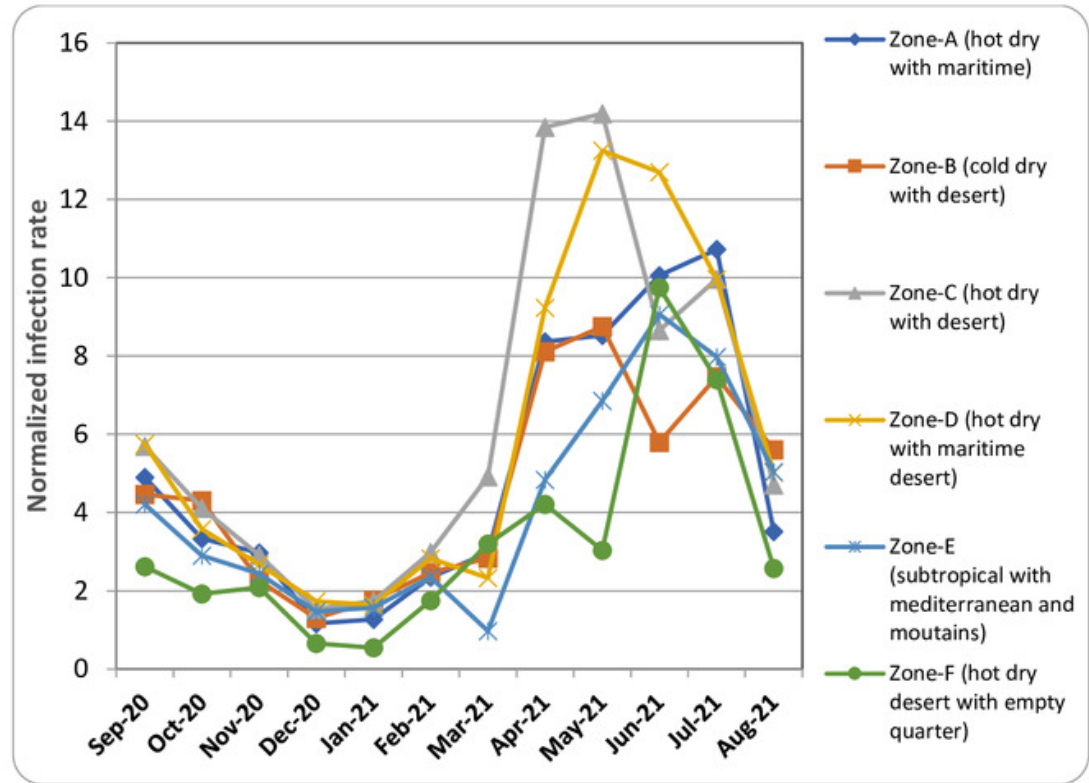

Figure-2: Normalized COVID-19 infection rate in different climatic zones. 
Figure 3

Figure-3: Recorded mean temperature in different climatic zones 


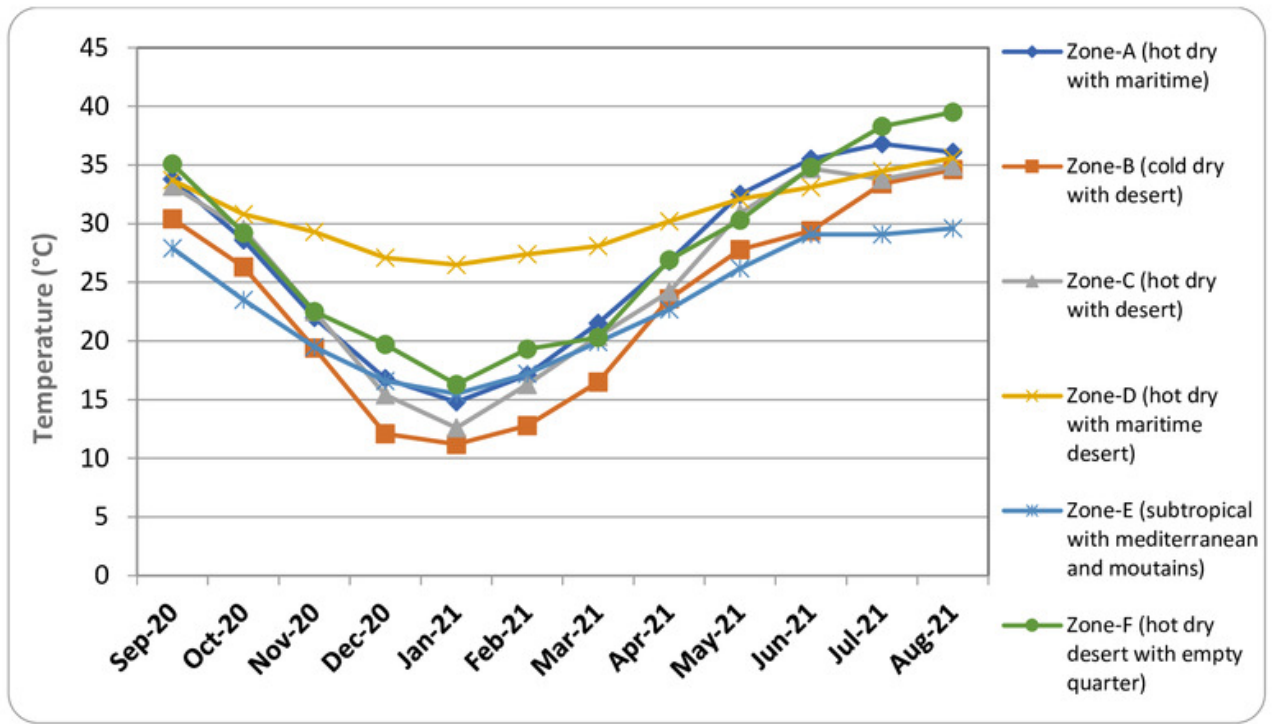

Figure-3: Recorded mean temperature in different climatic zones 
Figure 4

Figure-4: Humidity level recorded in different climatic zones 


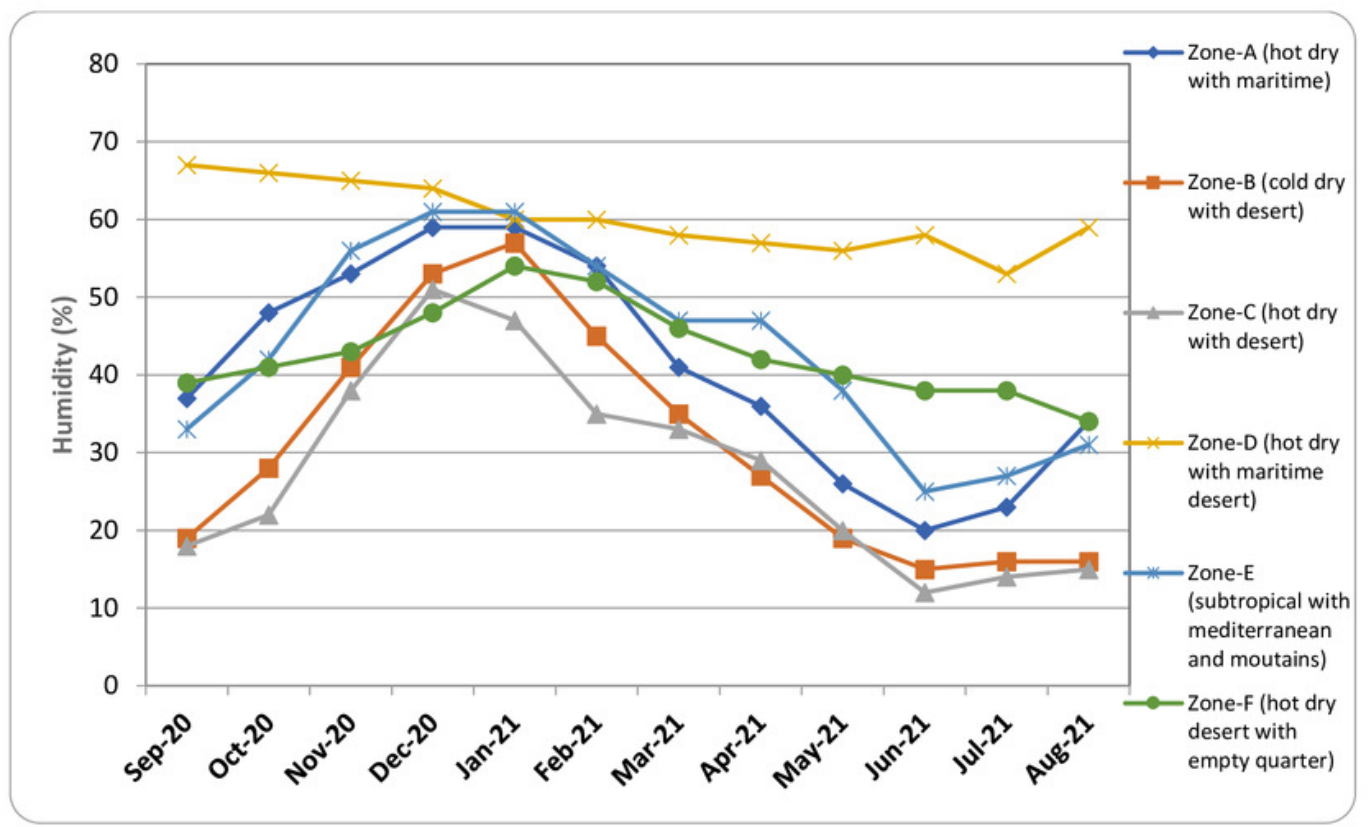

Figure-4: Humidity level recorded in different climatic zones 
Figure 5

Figure-5: Recorded average wind speed in different climatic zones 


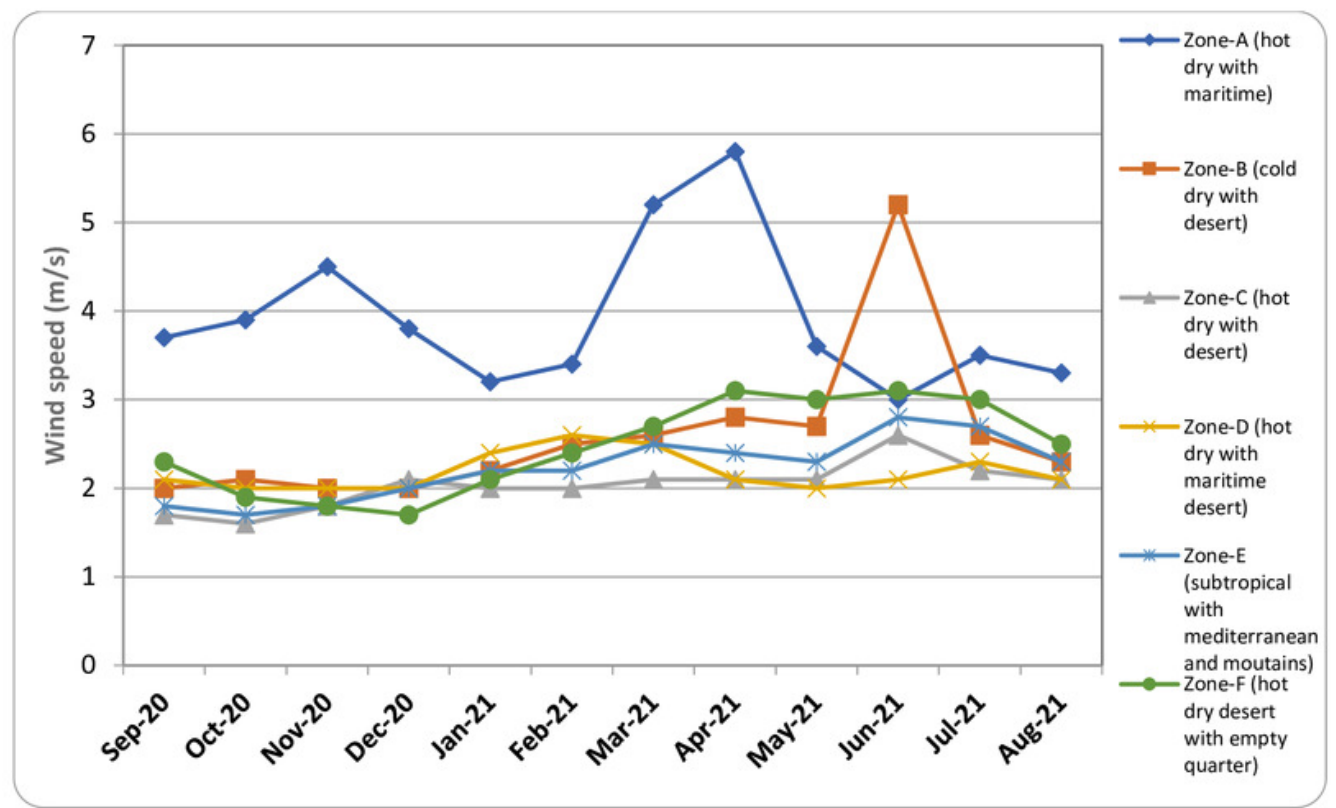

Figure-5: Recorded average wind speed in different climatic zones 
Figure 6

Figure-6: Sun exposure $\left(\mathrm{kwh} / \mathrm{m}^{2}\right)$ measured in different climatic zones 


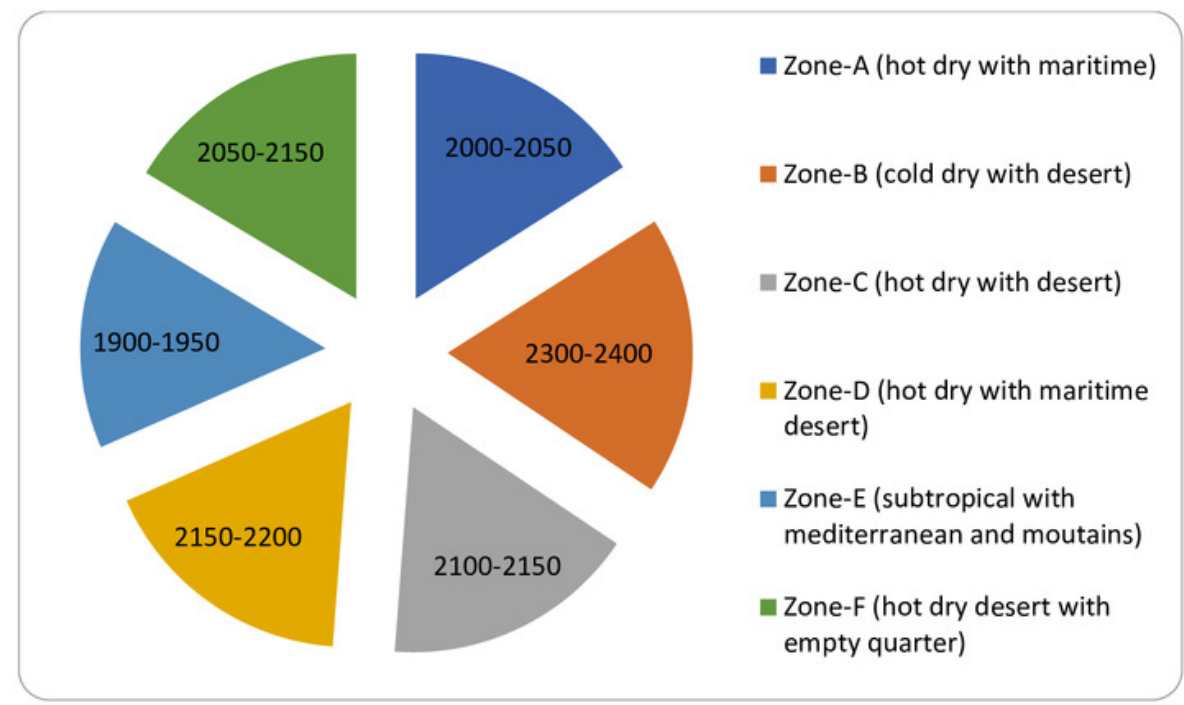

Figure-6: Sun exposure $\left(\mathrm{kwh} / \mathrm{m}^{2}\right)$ measured in different climatic zones 
Figure 7

Figure-7: Bivariate analysis between environmental factors and COVID-19 spread. 


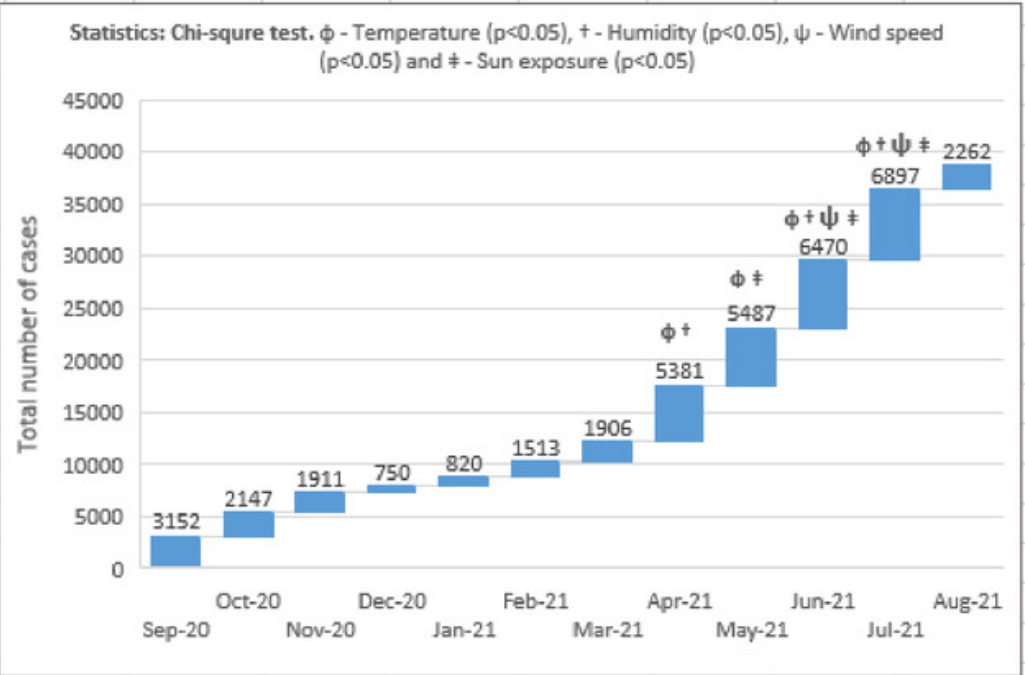

Figure-7: Bivariate analysis between environmental factors and COVID-19 spread. 